\title{
Reduction of Graphene Oxide: Controlled Synthesis by Microwave Irradiation
}

\author{
Endah Fitriani Rahayu*1, Bunnari', Andri Hardyansyah² \\ 'Department of Chemistry, Universitas Negeri Semarang \\ 2Pusat Penelitian Fisika LIPI-Serpong Kota Tangerang Selatan \\ *Corresponding author email: endah_danis@mail.unnes.ac.id
}

Received August 08, 2019; Accepted March 03, 2020; Available online March 15, 2020

\begin{abstract}
Graphene has been attracting enormous attention in the scientific community because of its unique properties and use for various applications. Graphene has been synthesized in various ways, one of which is the graphite oxidation method to form graphene oxide (GO). Reduction of GO to reduced graphene oxide (RGO) is necessary to recover the conjugated network and electrical conductivity, and for this research, this was achieved using microwave irradiation. Microwave synthesis provides an alternative method, saving more time in the reaction process. In this research, graphene was synthesized from graphite by the modified Hummers method and microwave irradiation. This research proves that graphene can be synthesized with a high-quality structure and in a shorter amount of time using microwave irradiation to reduce GO. With longer microwave exposure, less GO is present in the sample, as indicated by the absence of an $n-\pi^{*}$ electronic transition in the absorbance graph and the absence of oxide groups in the Fourier-Transform Infra-Red spectrum. With increasing microwave power, the reduction process is short-lived, and better quality RGO is produced. This study shows that the new reduction process occurs within 20 minutes with a power of 450 and 630 watts, but at 900 watts, the reduction of GO occurs within 10 minutes, as shown by UV-Vis and FTIR spectra.
\end{abstract}

Keywords: graphene, microwave, Hummers

\section{INTRODUCTION}

Graphene has been demonstrated by Novoselov et al. (2004), with easy isolation achieved by the exfoliation of graphite, and since then, graphene has been attracting enormous attention in the scientific community. This is due to its unique properties, such as being lightweight, thin, and flexible, and its promise for many potential applications such as durable display screens, electric circuits, supercapacitors (Emiru \& Ayele, 2017), transistors, transparent conducting electrodes, conductive polymer composites, energy storage materials, and solar cells. Graphene is a single plane layer of graphite. The unit cell of graphene contains two carbon atoms, and the lattice can be viewed as being formed by two sublattices, shown in Figure 1.

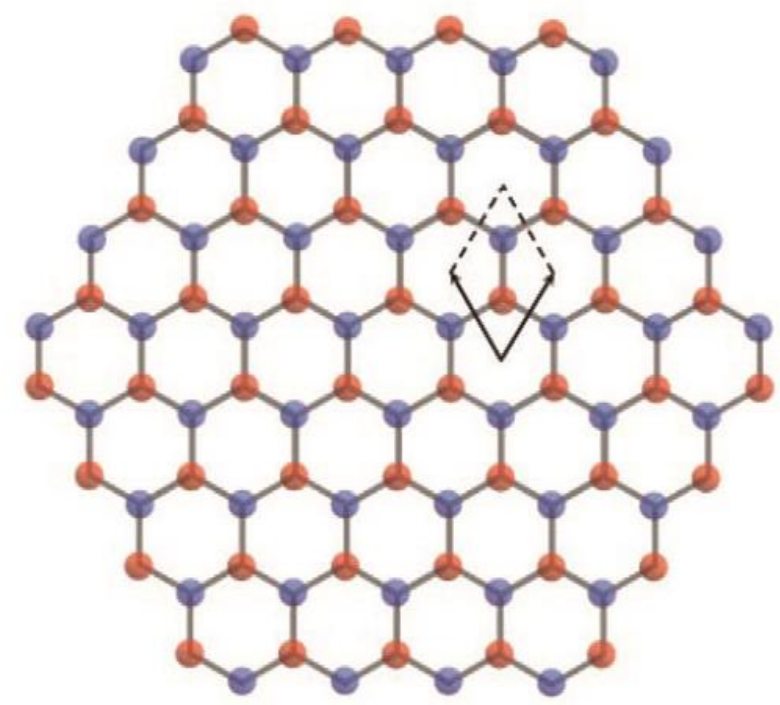

Figure 1. The two graphene sublattices (red and blue) (Avouris \& Dimitrakopoulos, 2012). 
Graphene has been synthesized in various ways and on different substrates. In fact, it was first synthesized by mechanical exfoliation. This is simple, low-budget technique and has been widely used in the synthesis of graphene. Unfortunately, these samples are usually available at a size of only several microns (or tens of microns, at best), have irregular shapes, and have an azimuthal orientation that is not deterministically controlled. Mechanical exfoliation can produce pristine graphene, but the process is complicated. Furthermore, the product size is small, which is limiting for the production of large-scale quantities (Emiru \& Ayele, 2017). Another method of synthesis graphene is chemical vapor deposition (CVD). Graphene has been grown by CVD from carbon-containing gases on catalytic metal surfaces and by surface segregation of Carbon dissolved in the bulk solution catalytic metals. CVD can produce graphene as thin films, containing a single or few layers, over large surface areas. However, CVD requires high temperatures, up to $1000^{\circ} \mathrm{C}$, along with a hydrocarbon gas flow as a precursor and pure hydrogen as a carrier gas. Epitaxial growth can also produce graphene with perfect structure and excellent properties, prepared by simply heating precursors materials and cooling down on a SiC crystal. Generally speaking, single or bi-layer graphene forms on the Si face of the crystal, whereas few-layer graphene grows on the $C$ face. However, the results are highly dependent on the parameters used. If the temperatures and pressure are too high, the growth of nanotubes, instead of graphene, can occur. Generally speaking, the graphitization of $\mathrm{SiC}$ was discovered in 1955, but it was regarded as an unwelcome side effect, instead of a method of preparing graphene (Enderlein, 2010).

Graphene is a carbon allotrope that consists of a flat monolayer of $\mathrm{sp}^{2}$ carbon atoms bonded and arranged in a honeycomb lattice. Graphene has some outstanding physical properties that make it extremely appealing for applications in electronics. The linear dispersion of the $\pi-\pi^{*}$ bands mainly leads to the conclusion that the transport of electrons in graphene occurs by the sublattice. Compared to another carbons materials, graphene contains higher mobility $\left(200,000 \mathrm{~cm}^{2} \mathrm{v}^{-1} \mathrm{~s}^{-1}\right.$; Zaaba et al., 2017), Young's modulus (1 TPa; Lee, Wei, Kysar, \& Hone, 2008), and thermal conductivity $\left(4840-5300 \times 10^{3} \mathrm{~W} / \mathrm{mK}\right.$; Zaaba et al., 2017). These properties make graphene a potential material for use in sector transistor elements and integrated circuits (Aroutiounian, Shmavonyan, Zadoyan, \& Gambaryan, 2013), energy storage, gas sensors (Choi, Lahiri, Seelaboyina, \& Kang, 2010), etc. Among the current methods of graphene synthesis, solution-processed routes are the most suitable for functionalization and bulk-scale production, offering the oxidation of graphite to graphene oxide (GO). The reduction of $\mathrm{GO}$ to reduced graphene oxide (RGO) is necessary to recover the conjugated network and electrical conductivity in these materials. The carboxyl, hydroxyl, or epoxy groups bonded on graphene and other atomic-scale lattice defects modify the electronic structure of graphene and serve as strong scattering centers that can affect the electrical transport (Ghorbani, Abdizadeh, \& Golobohstanfard, 2015). The reduction of $\mathrm{GO}$ by chemical or thermal routes has widely been accepted to prepare RGO, and in this work, microwave irradiation is used. (a)

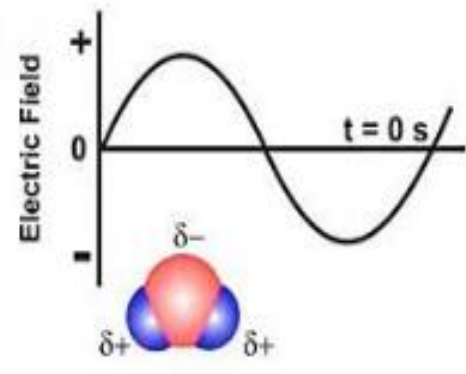

(b)

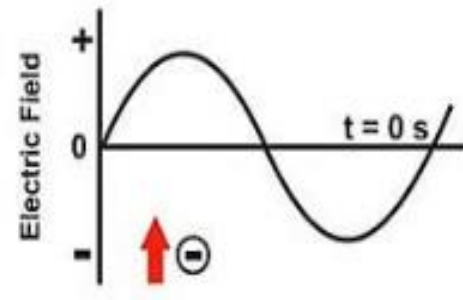

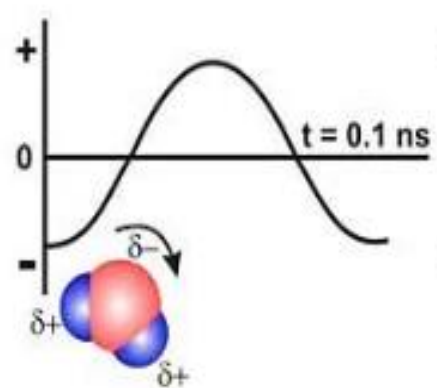
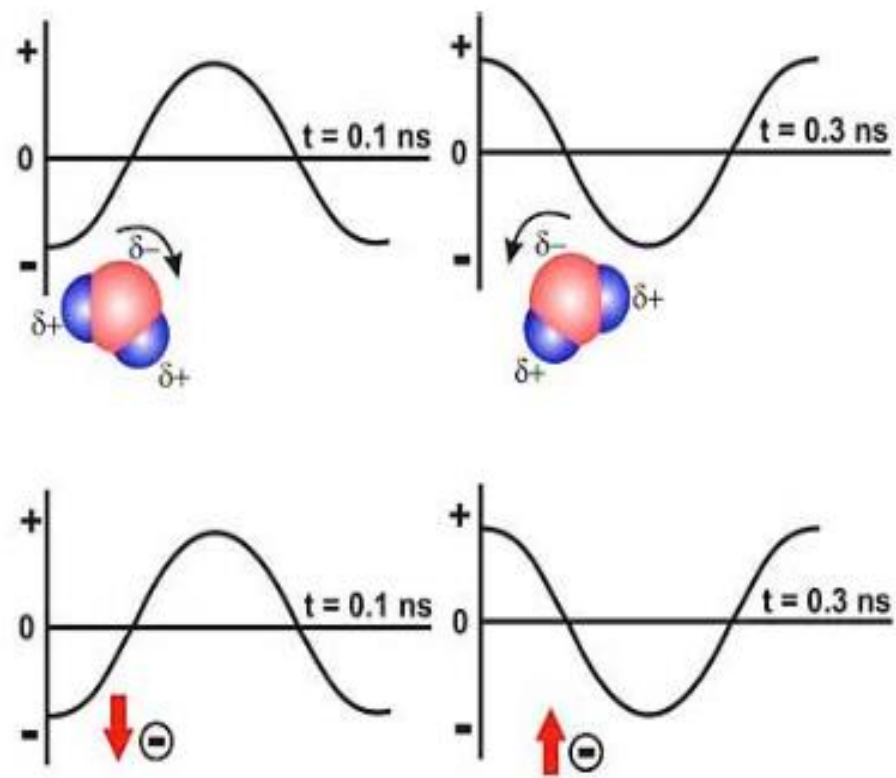

Figure 2. Two main heating mechanisms under microwave irradiation: (a) dipolar polarization and (b) ionic conduction (Saleh, Majeed, Nayak, \& Bhushan, 2017). 
Microwave chemistry is the science of applying microwave radiation to chemical reactions. Microwave synthesis represents a major breakthrough in synthetic chemistry methodology, marking a dramatic change in the way chemical synthesis is performed (Grewal, Kumar, Redhu, \& Shashikant, 2013). Conventional heating, known to be inefficient and time-consuming, has been recognized to be creatively limiting, too. Microwave synthesis gives us an alternative way to save more time in the reaction process. In liquid-phase syntheses of nanomaterials, microwave irradiation triggers heating by two mechanisms, namely, dipolar polarization and ionic conduction, as shown in Figure 2. In the dipolar polarization (or rotation) mechanism, the dipoles in the reaction mixture (for example, polar solvent molecules or reagents) are involved, whereas charged particles (free ions or ionic species) in a substance contribute to ionic conduction. When irradiated at microwave frequencies, the dipoles in the sample try to align themselves in the direction of the applied electric field.

\section{EXPERIMENTAL SECTION \\ Chemicals}

Materials used in this research are pro analysis grade graphite, $\mathrm{NaNO}_{3}, \mathrm{H}_{2} \mathrm{SO}_{4}, \mathrm{KMnO}_{4}, \mathrm{H}_{2} \mathrm{O}_{2}, \mathrm{HCl}$, ethanol, boric acid, nickel foam, $\mathrm{KOH}$, distilled water, and double-distilled water.

\section{Synthesis of Graphite Oxide}

The synthesis of graphite oxide was conducted by the Hummers method using reflux tools. At first, $1 \mathrm{~g}$ Graphite, $1 \mathrm{~g} \mathrm{NaNO}_{3}$, and $46 \mathrm{~mL} \mathrm{H}_{2} \mathrm{SO}_{4}$ were mixed in a round-bottom flask and distorted for 30 minutes at $<20^{\circ} \mathrm{C}$. Then, $6 \mathrm{~g}$ of $\mathrm{KMnO}_{4}$ was added, and the solution was distorted again for 30 minutes at the same temperature. Next, $80 \mathrm{~mL}$ of double distilled water was added slowly, and the mixture was allowed to stabilize for 30 minutes at $40^{\circ} \mathrm{C}$. This was followed by slow addition of $200 \mathrm{~mL}$ of double distilled water and $6 \mathrm{~mL}$ of $\mathrm{H}_{2} \mathrm{O}_{2}$, and the mixture was then stirred for 90 minutes at $75^{\circ} \mathrm{C}$ (Guerrero-Contreras \& Caballero-Briones, 2015).

The resulting $\mathrm{GO}$ was centrifuged for 30 minutes at $3500 \mathrm{rpm}$. This was followed by the addition of double distilled water to each bottle, and the sample was centrifuged, again, three times. These treatments were repeated with $10 \% \mathrm{HCl}$ and $10 \%$ ethanol. The $\mathrm{pH}$ was regularly checked, using a $\mathrm{pH}$ indicator, until the solution reached a $\mathrm{pH}$ value of 7 (Thirumal, Pandurangan, Jayavel, \& Ilangovan, 2016). The clear solution was centrifuged with $10 \%$ ethanol and collected. The resulting sediment was released into a petri dish and heated in an oven at $40^{\circ} \mathrm{C}$ for 24 hours.

\section{Reduction of GO Using a Microwave}

A solution of $1 \mathrm{mg} / \mathrm{mL} \mathrm{GO}$, which had been sonicated for 30 minutes, was placed in a microwave under 450, 600, and 900 watts of power. After the reduction process, the $10 \mathrm{~mL}$ solutions were collected at 1, 5, 10, 15, and 20 minutes (Tien et al., 2012).

\section{Characterization Techniques}

The changes in composition of the GO structure, as indicated by the absorbance graph, were observed using UV-Vis spectrophotometry. Moreover, Fouriertransform infrared (FTIR) testing was conducted to determine the functional groups formed during the synthesis process, and scanning electron microscopy (SEM) was conducted on graphite, its oxide, graphene, and boron graphene (BG) samples using INSPECT S50.

\section{RESULTS AND DISCUSSION Spectrophotometer Analysis}

The characterization by UV-Vis spectrophotometry showed the relationship between the wavelength (in nanometers) and the absorbance of the solution tested, showing the $\mathrm{GO}$ reduction to RGO following microwave irradiation synthesis. Figure 3 shows the spectra of RGO, synthesized by microwave irradiation at 450 watts.

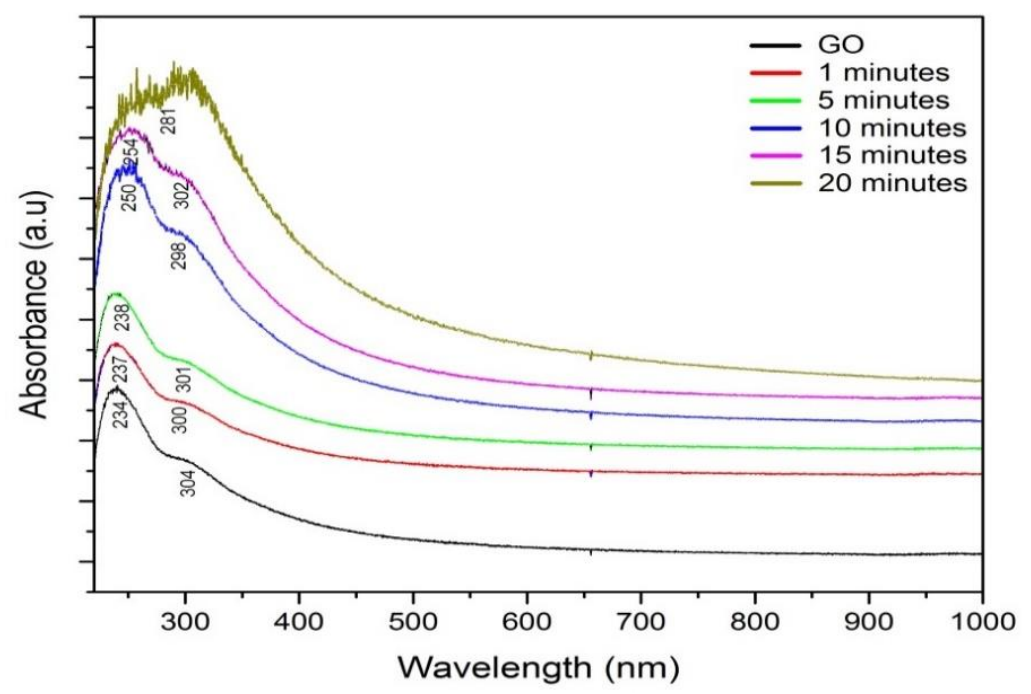

Figure 3. Spectra of RGO show the progress of the synthesis at 450 watts microwave power. 
The peaks were observed between 230 to $310 \mathrm{~nm}$, which is characteristic of $\mathrm{GO}$ or multilayer graphene. The absorption peak at $230 \mathrm{~nm}$ is related to the $\pi-\pi^{*}$ transition from the $\mathrm{C}=\mathrm{C}$ bond and the shoulder at $300 \mathrm{~nm}$ is related to the $\mathrm{n}-\pi^{*}$ transition from the $\mathrm{C}-$ $\mathrm{O}$ bond ( $\mathrm{Li} \&$ Bubeck, 2013). Figure 3 illustrates absorbance versus wavelength at 450 watts for six samples, which are 0 minutes (GO), 1 minute, 5 minutes, 10 minutes, 15 minutes, and 20 minutes after the microwave process with peaks at 234, 237, 238, 250, 254, and $281 \mathrm{~nm}$, respectively. At 20 minutes, the shoulder at $300 \mathrm{~nm}$ was lost, indicating that the $\mathrm{C}=\mathrm{O}$ bond on $\mathrm{GO}$ was reduced to graphene. Moreover, Figure 3 shows that longer microwave exposure times reduce more $\mathrm{GO}$, and Figure 4 shows that the color of the solution gets darker, turning from brownish-yellow to black, after exposure to microwave radiation; this indicates a rapid change in $\mathrm{C}=\mathrm{C}$ bonds (Tien et al., 2012).
Figure 5 shows the spectra of RGO following microwave irradiation at 630 watts. At 630 watts, the wavelength is greater than with 450 watts, meaning that $\mathrm{GO}$ is reduced faster with greater power. The two variations have peaks at 244, 246, 247, 248, 249 , and $250 \mathrm{~nm}$. The larger shift of the first peak, which is the $\pi-\pi^{*}$ orbital, shows that GO has been reduced and becomes graphene. In the three variations of mass and power, it can be seen that with longer the exposure times, increased microwave powers, and less mass, more $\mathrm{GO}$ is reduced. The increased reduction time also affects the color of the $\mathrm{GO}$ solution, which gets darker with longer reaction times. This shows that there is a change in structural composition, namely the reduction of functional groups in $\mathrm{GO}$ by microwave exposure. Figure 6 shows solutions of RGO after microwave irradiation at 630 watts.

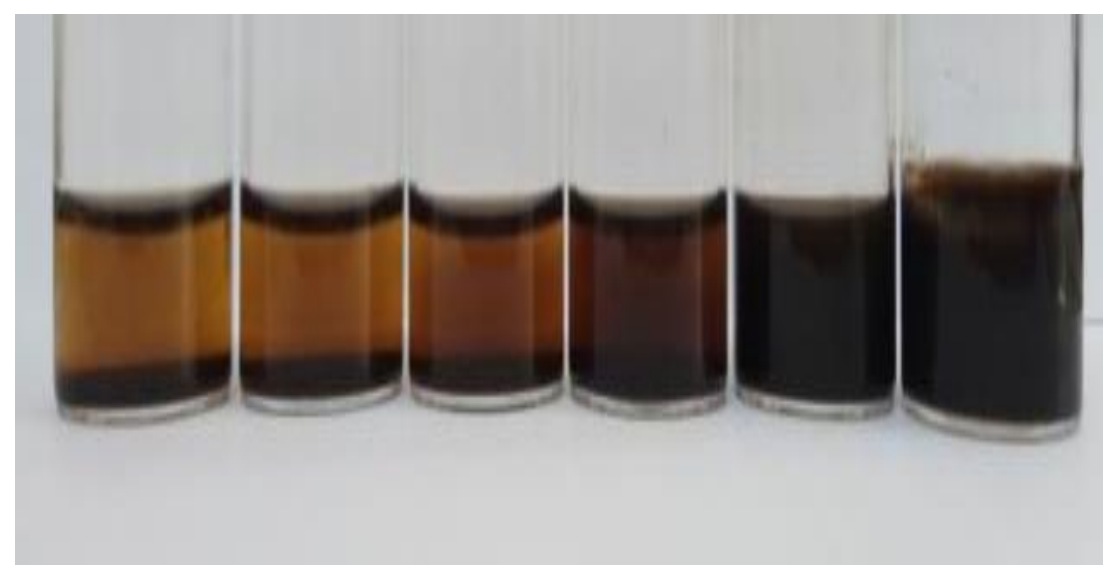

Figure 4. Irradiation time for each sample increases from left to right at 450 watts microwave power

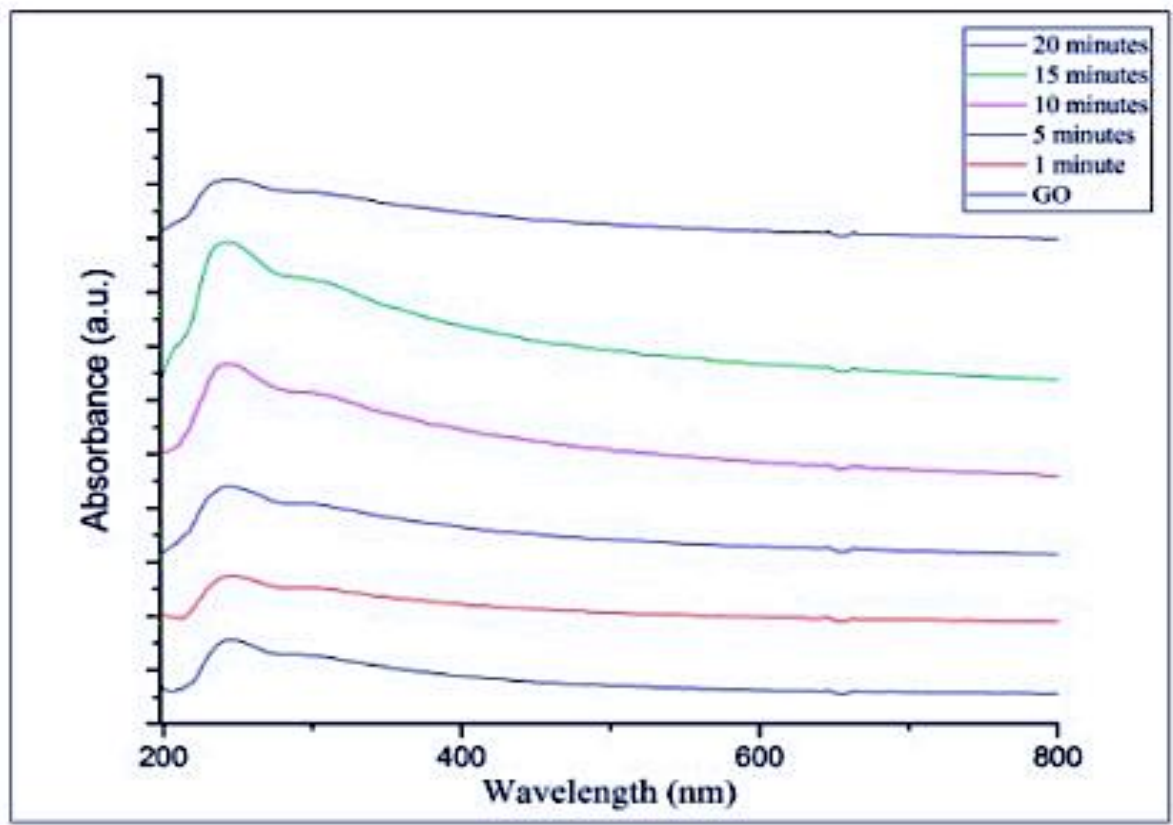

Figure 5. Spectra of RGO show the progress of the synthesis at 630 watts microwave power. 


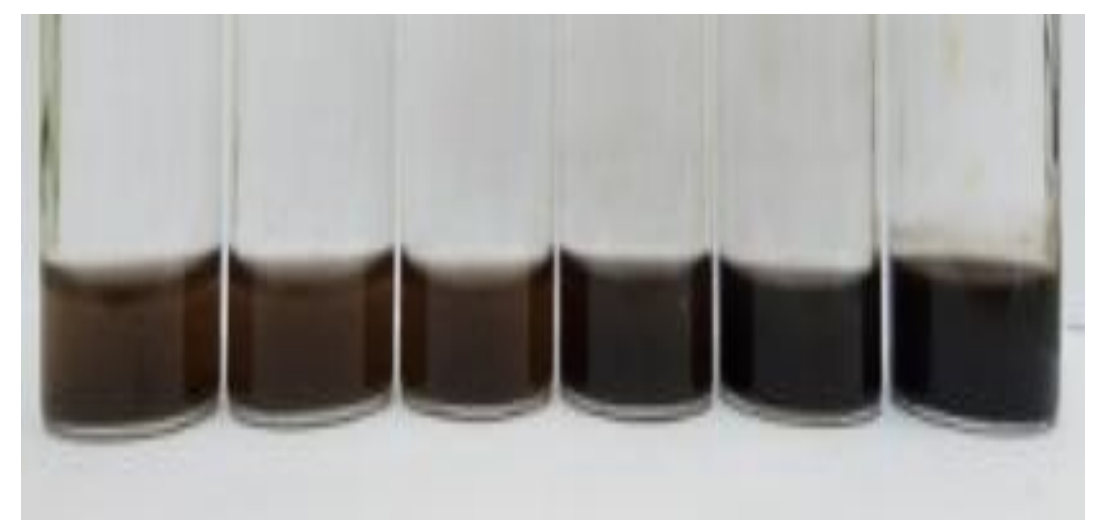

Figure 6. Irradiation time for each sample increases from left to right at 630 watts microwave power

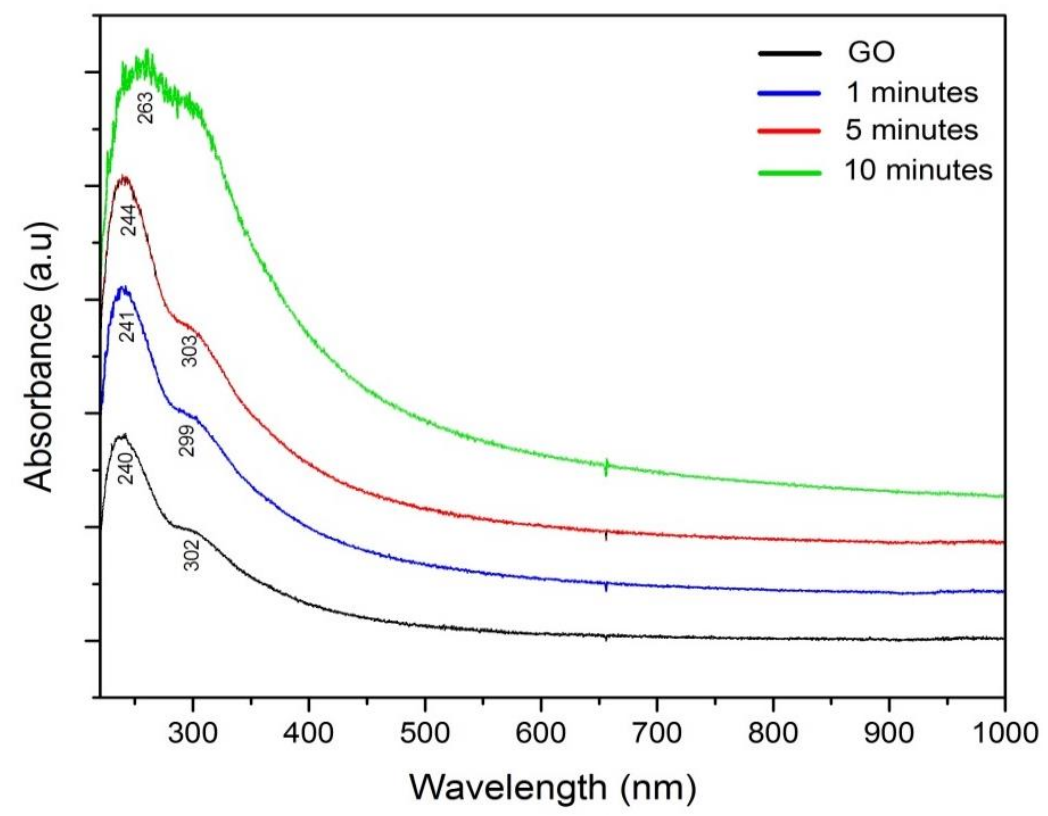

Figure 7. Spectra of RGO show the progress of the synthesis at 900 watts microwave power.

Figure 7 shows the absorbance/wavelength relationship of the RGO sample synthesized using 900 watts of power. There are four spectra of the RGO samples for microwave times of 1,5 , and 10 minutes. There are successive peaks at 240,241,244, and 263 $\mathrm{nm}$, respectively. After 1 and 5 minutes of irradiation, the reduction process showed a shoulder around 300 $\mathrm{nm}$. This shows that with up to 5 minutes of microwave irradiation using 900 watts of power, GO is not fully reduced, as indicated by the absorbance features of the electronic $\pi-\pi^{*}$ and $n-\pi^{*}$ transitions, which are characteristic of GO.

This treatment shows that, by using 900 watts of power, the reduction process takes place faster. After 10 minutes of the microwave process, the sample was characterized and contained only one peak at $263 \mathrm{~nm}$, and no shoulder was present around 300 $\mathrm{nm}$. This shows that $\mathrm{GO}$ is reduced to graphene, due to the absence of an $n-\pi^{*}$ electronic transition from the $\mathrm{C}-\mathrm{O}$ bond, and the reduction process takes place in a short amount of time (Tien et al., 2012).

\section{FTIR Characterization Analysis}

The FTIR test was conducted to analyze the functional groups in the samples produced at each stage. Graphite, as the main component, has a $\mathrm{C}=\mathrm{C}$ aromatic bond between each of its atoms in one layer, indicated by the peak at $1565 \mathrm{~cm}^{-1}$. Moreover, the $\mathrm{C}=\mathrm{C}$ alkene bond was also found in graphite, shown at $1684 \mathrm{~cm}^{-1}$. After oxidation, GO was dominated by an oxide group. In the GO spectra, there are peaks at $3397 \mathrm{~cm}^{-1}$, which belong to the $\mathrm{O}-\mathrm{H}$ stretching band, and at $1621 \mathrm{~cm}^{-1}$, which arise from the vibration of the $\mathrm{C}=\mathrm{C}$ aromatic bond. The oxidation results in several wave peaks, identified as $\mathrm{C}-\mathrm{O}$ bonds at 1060 $\mathrm{cm}^{-1}$ and $\mathrm{C}=\mathrm{O}$ bonds at $1730 \mathrm{~cm}^{-1}$, indicating carboxylic acids and carbonyl groups at the edges of GO. Moreover, the absorption peaks at $1660 \mathrm{~cm}^{-1}$ and $1060 \mathrm{~cm}^{-1}$, respectively, correspond to the stretching vibration of $\mathrm{C}-\mathrm{O}$ from the carboxylic acids and $\mathrm{C}-\mathrm{OH}$ from alcohol. The presence of this oxygencontaining group, therefore, revealed that graphite was oxidized (Shahriary \& Athawale, 2014). 
The results of the FTIR (Figure 8), as well as the absorbance spectra in Figure 3, reveal that $\mathrm{GO}$ has been reduced properly to RGO. This is indicated by the small amount of absorption at the peak around 1033 $\mathrm{cm}^{-1}$ (C-O stretching) and $1704 \mathrm{~cm}^{-1}$, which belongs to the $\mathrm{C}=\mathrm{O}$ bond. Moreover, the increased absorption of $\mathrm{C}=\mathrm{C}$ aromatic bonds at $1573 \mathrm{~cm}^{-1}$ is an indication of RGO formation and increments in carbon content present in RGO, compared to those in GO compounds. After the reduction of $\mathrm{GO}$, the $\mathrm{O}-\mathrm{H}$ bonds disappeared and had very little absorption intensity at $3371 \mathrm{~cm}^{-1}$. Further, RGO no longer showed the absorbance at $2339 \mathrm{~cm}^{-1}$, which is a $\mathrm{CO}_{2}$ bond group $(\mathrm{O}=\mathrm{C}=\mathrm{O})$. This indicates that the synthesis of RGO was successful in removing the $\mathrm{O}-\mathrm{H}$ bonds and the trapped $\mathrm{CO}_{2}$.

Based on the spectra in Figure 8, the reduction process yields the best graphene with 900 watts of power. At this power, the reduction process runs shorter, and the graphene produced is of better quality than the reduction process using 450 watts of power. With 450 watts of power, the graphene produced still contains $\mathrm{C}=\mathrm{O}$ bonds, which is indicated by the peak at $1733 \mathrm{~cm}^{-1}$. $\mathrm{C}-\mathrm{O}$ and $\mathrm{O}-\mathrm{H}$ bonds are also still present, indicated by peaks at $1060 \mathrm{~cm}^{-1}$ and $3422 \mathrm{~cm}^{-1}$, respectively. Thus, the reduction process with 450 watts of power is imperfect because the graphene produced still contains oxygen groups.

\section{SEM Characterization Analysis}

The SEM results from graphite, GO, and graphene presented in Figure 9, showing the particle size to be square, thick, wide, grey-black in colour, and with an irregular surface structure. Furthermore, a thick morphology, consisting of very tight graphene piles resembling solid crystals, was revealed for graphite (Hutapea, Amri, \& Irianty, 2018). In GO, the oxide group that formed weakened the bonds between the carbon layers (Shao et al., 2012). Therefore, the SEM results showed a morphology with a shape like a folded sheet of fabric, but the sheet is quite thick, due to the presence of several layers (Faiz \& Susanti, 2015). Moreover, graphene has a one-layer structure, and its morphology was shown as a thin sheet. In its structure, there was no oxide functional group, due to the conducted reduction process by microwave irradiation.

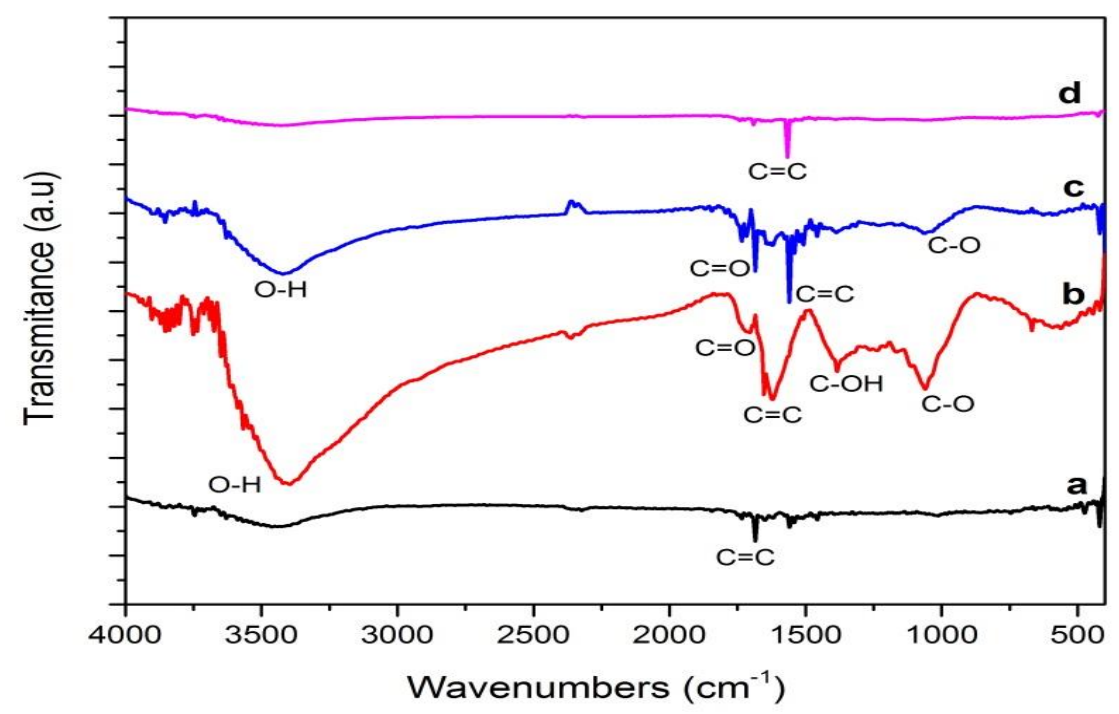

Figure 8. Infrared spectra of a) graphite, b) GO, and c) RGO at a power of 450 watts and d) RGO with a power of 900 watts.

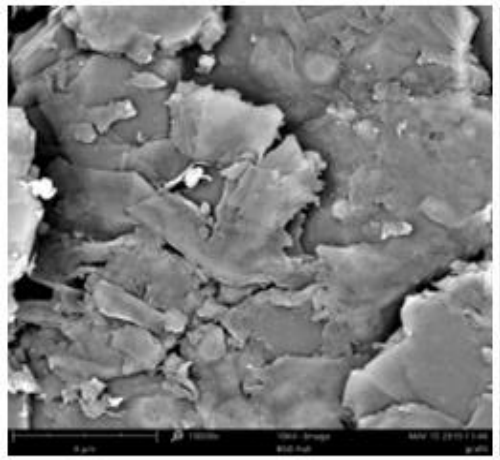

a

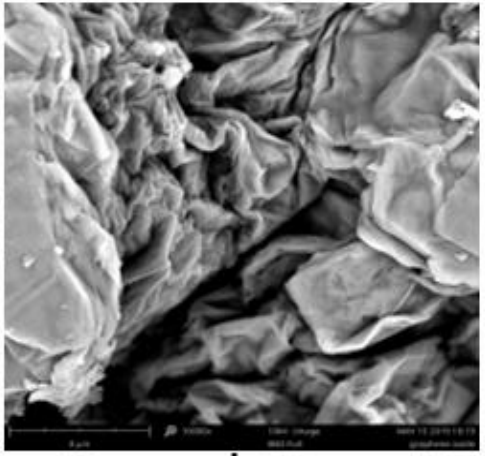

b

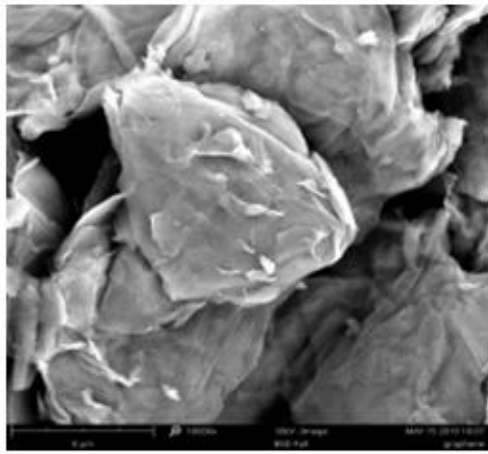

C

Figure 9. SEM micrographs of a) graphite, b) GO, and c) graphene at 10,000x magnification. 


\section{CONCLUSIONS}

In summary, considerable research has been devoted to the synthesis of graphene materials via the GO precursor in recent years. Of various reduction approaches, the microwave approach provides a fast, economical, and environmentally friendly method for the production of desirable quality graphene materials. This research proves that graphene can be synthesized using microwave irradiation, yielding high-quality structures, to reduce GO. More prolonged microwave exposure resulted in more reduced GO, as shown by the absence of an $n-\pi^{*}$ electronic transition in the absorbance graph and the absence of oxide groups in the FTIR spectra. As the microwave power is increased, the reduction process occurs more quickly, and better quality RGO is produced.

\section{REFERENCES}

Aroutiounian, V., Shmavonyan, G. S., Zadoyan, O. A., Gambaryan, K. M., \& Zadoyan, A. M. (2014). Investigation of photoelectrical properties of epitaxially grown heterojunction thermophotovoltaic cells. Journal of Contemporary Physics, 49(6), 258-263.

Avouris, P., \& Dimitrakopoulos, C. (2012). Graphene: Synthesis and applications. Materials Today, 15(3).

Choi, W., Lahiri, I., Seelaboyina, R., \& Kang, Y. S. (2010). Synthesis of graphene and its applications: A review. Critical Reviews in Solid State and Materials Sciences, 35(1), 52-71.

Emiru, T. F. \& Ayele, D. W. (2017). Controlled synthesis, characterization, and reduction of graphene oxide: A convenient method for large scale. Egyptian Journal of Basic and Applied Science, 4(0), 74-79.

Enderlein, C. (2010). Dissertation: Graphene and its interaction with different substrates studied by angular-resolved photoemission spectroscopy. Freie Universitaet Berlin.

Faiz, R., \& Susanti, D. (2015). Analisis pengaruh massa reduktor zinc terhadap sifat kapasitif superkapasitor. Material Graphene, 4(1), 95100.

Ghorbani, M., Abdizadeh, H., \& Golobohstanfard, M. R. (2015). Reduction of graphene oxide via modified hydrothermal method. Procedia Material Science, $17(0)$, 326-330.

Guerrero-Contreras, J., \& Caballero-Briones, F. (2015). Graphene oxide powders with different oxidation degree, prepared by synthesis variations of the Hummers method. Materials Chemistry and Physics, 153, 209-220.

Grewal, A. S., Kumar, K., Redhu, S., \& Shashikant, B. (2013). Microwave assisted synthesis: A green chemistry approach. International Research Journal of Pharmaceutical and Applied Science 3(5), 278-285

Hutapea, M., Amri, A., \& Irianty, R. S. (2018). Peluruhan batang grafit baterai bekas dengan metode electrochemical exfoliationmenggunakan pelarut amonium sulfat dan kalium sulfat. Jom FTEKNIK, 5(2), 17.

Li, H., \& Bubeck, C. (2013). Photoreduction processes of graphene oxide and related applications. Macromolecular Research, 21 (3), 290-297.

Lee, C., Wei, X., Kysar, J. W., \& Hone, J. (2008). Measurement of the elastic properties and intrinsic strength of monolayer graphene. Science, 321(18), 385-388.

Novoselov K. S., Geim A. K., Morozov S. V., Jiang D., Zhang Y., Dubonos S. V., Grigorieva L. I., \& Firsov A. A. (2004). Electric field effect in atomically thin carbon films. Science, 303(10), 666.

Saleh, T. A., Majeed, S., Nayak, A., \& Bhushan, B. (2017). Principles and advantages of microwave-assisted methods for synthesis of nanomaterials for water purification. Advanced nanomaterials for water engineering, treatment, and hydraulics, Chapter 3. Researchgate Publication. DOI: 10.4018/978-1-5225-2136$\underline{5 . c h 003}$

Shahriary, L., \& Athawale, A. A. (2014). Graphene oxide synthesized by using modified Hummers approach. International Journal of Renewable Energy and Environmental Engineering, 2(1), 58-63.

Shao, G., Lu, Y., Wu, F., Yang, C., Zeng, F., \& Wu, Q. (2012). Graphene oxide: The mechanisms of oxidation and exfoliation. Journal of Materials Science, 47(10), 4400-4409.

Thirumal, V., Pandurangan, A., Jayavel, R., \& llangovan, R. (2016). Synthesis and characterization of boron doped graphene nanosheets for supercapacitor applications. Synthetic Metals, 220, 524-532.

Tien, H. N., Luan, V. H., Cuong, T. V., Kong, B.-S., Chung, J. S., Kim, E. J., \& Hur, S. H. (2012). Fast and simple reduction of graphene oxide in various organic solvents using microwave irradiation. Journal of Nanoscience and Nanotechnology, 12(7), 5658-5662.

Zaaba, N. I., Foo, K. L., Hashim, U., Tan, S. J., Liv, W.-W., \& Voon, C. H. (2017). Synthesis of graphene oxide using modified Hummers method: Solvent influence. Procedia Engineering, 184(0), 469-477. 